\title{
Non-Invasive Assessment of Liver Fibrosis by Vibration-Controlled Transient Elastography (Fibroscan®)
}

\author{
Sandrin Laurent ${ }^{1}$, Oudry Jennifer ${ }^{1}$, Bastard Cécile ${ }^{1}$, \\ Fournier Céline ${ }^{1}$, Miette Véronique ${ }^{1}$ and Mueller Sebastian ${ }^{2}$ \\ ${ }^{1}$ Echosens, \\ ${ }^{2}$ University of Heidelberg, \\ ${ }^{1}$ France \\ ${ }^{2}$ Germany
}

\section{Introduction}

Chronic liver diseases result in fibrosis ultimately leading to cirrhosis, a liver end stage disease with high mortality and life threatening complications such as hepatocellular carcinoma. Thus far, no treatment options exist to cure and stop fibrosis progression except organ replacement by liver transplantation. This clinically unsatisfactory situation justifies the enormous interest in quantifying and monitoring fibrosis progression. Though liver biopsy remains the gold standard for assessing liver fibrosis, non invasive procedures are being developed for many years to overcome its complications (Bravo et al. 2001), sampling error and interobserver variability (Abdi et al. 1979; Bedossa et al. 2003; Cadranel et al. 2001). Fibrosis and activity marker scores based on several blood parameters from a simple blood test have been developed to assess liver fibrosis and activity as obtained by liver biopsy Many efforts have been invested to identify serum markers that allow the diagnosis of cirrhosis from simple blood tests (Poynard et al. 2004). However those scores are indirect and reflect the fibrogenetic activity. Thus they do not correlate with the absolute amount of fibrotic tissue within the liver.

It is now well established that fibrosis increases liver stiffness. Liver palpation (Fig. 1) is a routine medical practice that has been used since the beginning of medicine to assess liver stiffness. Though, palpation suffers from major limitations: it is highly subjective, very operator dependent and sometimes even impossible to perform. Recently, quantitative elastography emerged as a means to assess liver fibrosis non-invasively. Nowadays Vibration-Controlled Transient Elastography (VCTETM) is by far the most clinically validated quantitative elastography technique and VCTETM based device, Fibroscan ${ }^{\circledR}$ (Echosens, France), has emerged as the reference tool for liver stiffness measurement. As a fact, Fibroscan ${ }^{\circledR}$ is more and more used in routine clinical practice as an alternative method to liver biopsy in patients with chronic liver diseases.

The chapter is organized as follows: Section 2 covers quantitative elastography; the main quantitative elastography techniques are described with a strong focus on the most clinically validated technique: VCTETM ${ }^{\mathrm{TM}}$. Fibroscan ${ }^{\circledR}$ device is described in Section 3; the examination 
procedure is described. Advantages and limitations of the device are detailed. Applications of VCTE ${ }^{\mathrm{TM}}$ in hepatology are described in Section 4 . The role of liver stiffness as a clinically relevant parameter will be pointed out. In Section 5, the pressure-stiffness-fibrosis sequence hypothesis is addressed. Eventually, discussion and conclusion are drawn in Section 6 and Section 7 , respectively.

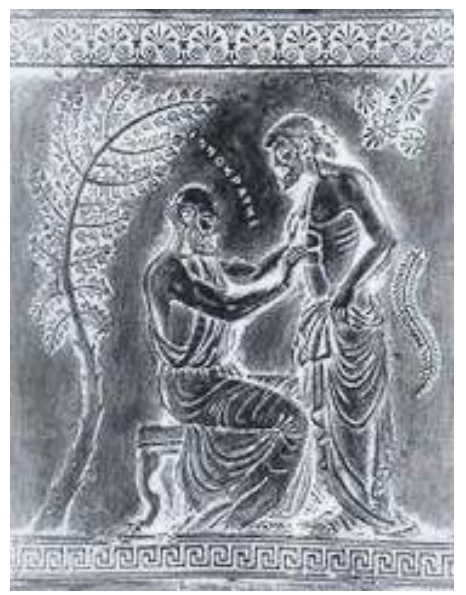

Fig. 1. Liver hand palpation: "The living are soft and yielding; the dead are rigid and stiff", Lao Tzu, (6th century BCE).

\section{Quantitative elastography}

\subsection{Elastography techniques}

It was a matter of time to see the development and emergence of sophisticated techniques such as elastography to quantitatively and non-invasively measure liver stiffness. Elastography is a recent field of research that started in the 80 s to propose a reproducible and operator-independent alternative technique to hand palpation. Elastography techniques may be divided into two groups: qualitative elastography and quantitative elastography.

Qualitative elastography is now widely available on ultrasound scanners, it provides a qualitative color image that gives an interpretation of stiffness without providing any number. Basically, while the operator moves the ultrasound transducer at the skin surface of the body, the scanner measures the quasi static displacements within the tissues. A map representing the inverse of the displacement is displayed usually in color: the larger the displacement, the softer the tissue. While this technique may be helpful in radiology to identify focal lesions, it is definitively not adapted to quantify stiffness.

Quantitative elastography techniques rely on the use of low frequency shear waves. Indeed the velocity of these mechanical waves is directly related to the stiffness. Thus all quantitative elastography techniques combine a means to generate shear waves and an imaging technique to measure the propagation of the generated shear waves.

\subsection{Physics of elastography}

From a physical and mechanical point of view, stiffness can be defined as the shear modulus, $\mu$, or the Young's modulus, E. These moduli describe the mechanical response of a 
medium under shear stress and longitudinal stress, respectively. The theory of linear elasticity is based on this relationship between stress and strain and states that the deformation of a material is directly proportional to the applied stress, $\sigma=\mathrm{E} \varepsilon$, where $\sigma$ is the stress applied to the material, and $\varepsilon$ is the strain induced in the material. The Young's modulus $E$ is expressed in kilopascals $(\mathrm{kPa})$ and represents the resistance of material to deformation. This law, known as Hooke's law, gives the relationship between the strain $\varepsilon$, the Young's modulus and the stress $\sigma$. A rod, length $L$, of elastic material can be seen as a linear spring. Under a stress $\sigma$, it will experience an extension $\Delta \mathrm{L}$ :

$$
\begin{gathered}
\sigma=E \varepsilon \\
\Delta L=\frac{\sigma L}{E}
\end{gathered}
$$

The relationship between the Young's modulus E, the Poisson coefficient $v$ and the Lamé coefficients $\lambda$ and $\mu$ (also known as compression and shear moduli), is given by:

$$
\begin{aligned}
& E=\mu \frac{3 \lambda+2 \mu}{\lambda+\mu} \\
& v=\frac{\lambda}{2(\lambda+\mu)}
\end{aligned}
$$

Biological tissues are mainly composed of water. The compression modulus $\lambda$ is several Giga Pascal; it is thus very large compared to the shear modulus of soft biological tissues (several kilo Pascal) (Sarvazyan et al. 1995). With $\lambda>>\mu$, it yields that $v \approx 0.5$ which is characteristic of a quasi-incompressible medium. Eventually, in soft medium, the Young's modulus $E$ simplifies to:

$$
E=3 \mu
$$

Interestingly, under some simplification hypothesis, the shear modulus can be deduced from the shear wave velocity, $\mathrm{V}_{\mathrm{s}}$, and the mass density, $\rho$ :

$$
\begin{aligned}
& \mu=\rho V_{s}^{2} \\
& E=3 \rho V_{s}^{2}
\end{aligned}
$$

Since the soft body tissues mass density is almost constant $\left(1000 \mathrm{~kg} / \mathrm{m}^{3}\right)$, the Young's modulus $E$ can be obtained by measuring the velocity of shear waves. Thus shear waves are the foundation of quantitative elastography techniques.

\subsection{Background of quantitative elastography}

Quantitative elastography techniques, also called dynamic elastography techniques, have the advantage of allowing a quantitative imaging and better resolution than the static elastography techniques. However, they require more complex equipment for the generation of shear waves (monochromatic, transient) and imaging devices (ultrafast ultrasound, magnetic resonance imaging) able to measure shear wave induced displacement with a high resolution. There are basically two groups of quantitative elastography techniques depending on the shear wave generation method: remote generation using 
radiation force and mechanical vibration. The shear wave frequency content may also be different: harmonic or transient.

In transient elastography techniques, the propagating shear wave results from a transient (impulsive or short tone burst) excitation of the tissue. Indeed, an important feature of transient elastography techniques is that the vibration be transient to avoid reflections and interferences occurring within the tissues. The transient shear wave travels through the tissues within tens of milliseconds which implies that the ultrasound-based imaging modality be ultrafast to follow its propagation. Harmonic elastography techniques are using a continuous vibration at a fixed frequency. Several quantitative elastography techniques (see Table 1) were proposed to assess liver stiffness as a marker of pathological state. Advantages and limitations of quantitative elastography techniques are summarized in Table 2.

\begin{tabular}{|c|c|c|c|}
\cline { 2 - 4 } \multicolumn{1}{c|}{} & Imaging modality & $\begin{array}{c}\text { Shear wave generation } \\
\text { mode }\end{array}$ & Frequency \\
\hline $\begin{array}{c}\text { Vibration-Controlled } \\
\text { Transient Elastography } \\
\text { (VCTETM) }\end{array}$ & Ultrasound & $\begin{array}{c}\text { Mechanical vibration } \\
\text { Transient }\end{array}$ & $\begin{array}{c}\text { Fixed } \\
50 \mathrm{~Hz}\end{array}$ \\
\hline $\begin{array}{c}\text { Magnetic Resonance } \\
\text { Elastography } \\
\text { (MRE) }\end{array}$ & $\begin{array}{c}\text { Magnetic resonance } \\
\text { imaging }\end{array}$ & $\begin{array}{c}\text { Mechanical vibration } \\
\text { Harmonic }\end{array}$ & Fixed \\
$60 \mathrm{~Hz}$ \\
\hline $\begin{array}{c}\text { Acoustic Radiation } \\
\text { Force Impulse (ARFI) }\end{array}$ & Ultrasound & $\begin{array}{c}\text { Radiation force } \\
\text { Transient }\end{array}$ & Wideband \\
\hline $\begin{array}{c}\text { Supersonic Shear } \\
\text { Imaging (SSI) }\end{array}$ & Ultrasound & $\begin{array}{c}\text { Radiation force } \\
\text { Transient }\end{array}$ & Wideband \\
\hline
\end{tabular}

Table 1. Quantitative elastography techniques for liver stiffness measurement.

\begin{tabular}{|c|c|c|}
\hline & Advantages & Limitations \\
\hline $\begin{array}{l}\text { Vibration-Controlled } \\
\text { Transient Elastography } \\
\text { (VCTETM) }\end{array}$ & $\begin{array}{c}\text { Ease of use } \\
\text { Highly standardized } \\
\text { Controlled shear frequency } \\
\text { Transient shear wave } \\
\text { Large clinical validation }\end{array}$ & Ascites \\
\hline $\begin{array}{l}\text { Magnetic Resonance } \\
\text { Elastography } \\
\text { (MRE) } \\
\end{array}$ & $\begin{array}{c}\text { Controlled shear frequency } \\
\text { Penetration depth } \\
\text { 2D stiffness map } \\
\end{array}$ & Cost \\
\hline $\begin{array}{l}\text { Acoustic Radiation } \\
\text { Force Impulse (ARFI) }\end{array}$ & $\begin{array}{l}\text { Image guidance } \\
\text { Transient shear wave }\end{array}$ & $\begin{array}{c}\text { Absence of shear wave control } \\
\text { High intensity ultrasound } \\
\text { Penetration depth } \\
\text { Limited clinical validation }\end{array}$ \\
\hline $\begin{array}{l}\text { Supersonic Shear } \\
\text { Imaging (SSI) }\end{array}$ & $\begin{array}{l}\text { Image guidance } \\
\text { Transient shear wave }\end{array}$ & $\begin{array}{l}\text { Absence of shear wave control } \\
\text { High intensity ultrasound } \\
\text { Penetration depth } \\
\text { Absence of clinical validation }\end{array}$ \\
\hline
\end{tabular}

Table 2. Advantages and limitations of quantitative elastography techniques. 


\subsubsection{Radiation force based elastography}

Radiation force based elastography uses high intensity ultrasound beams to induce displacements and tissue heating inside the liver remotely. Acoustic radiation force is applied to absorbing and/or reflecting materials in the propagation path of acoustic waves. This phenomenon is caused by a transfer of momentum from the acoustic wave to the propagation medium. The spatial distribution of the radiation force field is determined by both the acoustic excitation parameters and the tissue properties.

ARFI technique (Nightingale et al. 2003; Palmeri et al. 2008) involves the mechanical excitation of tissue using localized, focused, impulsive radiation force excitations. This results in shear-wave propagation away from the region of excitation. The mechanical excitation occurs along the acoustic wave propagation path and within the focal region of the acoustic beam. The resulting displacement response is ultrasonically tracked through time using an abdominal ultrasound transducer combined with a dedicated ultrasound scanner. Direct inversion methods are then applied to estimate the associated shear velocity.

Supersonic shear imaging (Bercoff et al. 2004; Muller et al. 2009) relies on the use of radiation force and a high frame rate ultrasound scanner (Sandrin et al. 2002). The medium is illuminated by a supersonic Mach cone: ultrasounds are focused successively at different increasing depths. The different spherical waves generated by each focus then interfere along a Mach cone in which the source is spreading faster than the shear wave generated and creates a plane wave front in the imaging plane. The ultrasound imaging system is then used to visualize the entire imaging plane with a good temporal resolution in a single acquisition typically 5000 to 20000 frames per second. Maps of the Young's modulus are estimated by inverse problems from the time of flight of the shear wave front.

Generating shear waves within the liver using radiation force requires high intensity ultrasound beams which induce liver tissue heating. Thermal safety issues related to incident radiation force pulses have been studied (Fahey et al. 2006; Palmeri \& Nightingale 2004). It required the development of special cooling time sequences to prevent overheating of liver tissues. As a consequence of the relative low energetic transfer efficacy, the amplitude of the remotely induced displacements remains low and the penetration depth of radiation force based elastography technique is thus limited.

\subsubsection{Mechanical vibration based elastography}

Mechanical vibration based elastography techniques are using a mechanical vibrator to induce shear waves into the body. In Magnetic Resonance Elastography (MRE) (Muthupillai et al. 1995), a nuclear magnetic resonance imaging (MRI) method is used for quantitatively mapping the physical response of the tissues to an excitation of low frequency typically between $50 \mathrm{~Hz}$ and $80 \mathrm{~Hz}$ (Klatt et al. 2006; Rouviere et al. 2006). MRE showed promising results especially for 2D mapping of tissue stiffness.

Vibration-Controlled Transient Elastography (Castera et al. 2005; Sandrin et al. 2003; Sandrin et al. 2002; Ziol et al. 2005) is based on a single ultrasound transducer mounted on the axis of a mechanical actuator (Fig. 2). The ultrasound transducer ( $3.5 \mathrm{MHz}$ ) is used in pulse-echo mode to measure the displacements induced in a medium by the propagation of a low-frequency $(50 \mathrm{~Hz})$ shear wave. Interestingly the low frequency shear wave and the ultrasound are generated by the same piston-like transducer. The ultrasound beam coincides with the vibrator axis. Under the assumption of homogeneity, the symmetry considerations impose that the displacements on the axis of the transducer be purely 
longitudinal. Diffraction effects from the piston-like transducer result in longitudinally polarized shear wave on the axis of symmetry (Sandrin et al. 2004). The displacements induced by the shear wave in the medium are measured using cross-correlation of successive ultrasound lines acquired at high frame rate. A spatial-temporal strain map is computed from the recorded displacements. The shear wave speed is calculated based on the slope of the wave front visualized in the strain map.

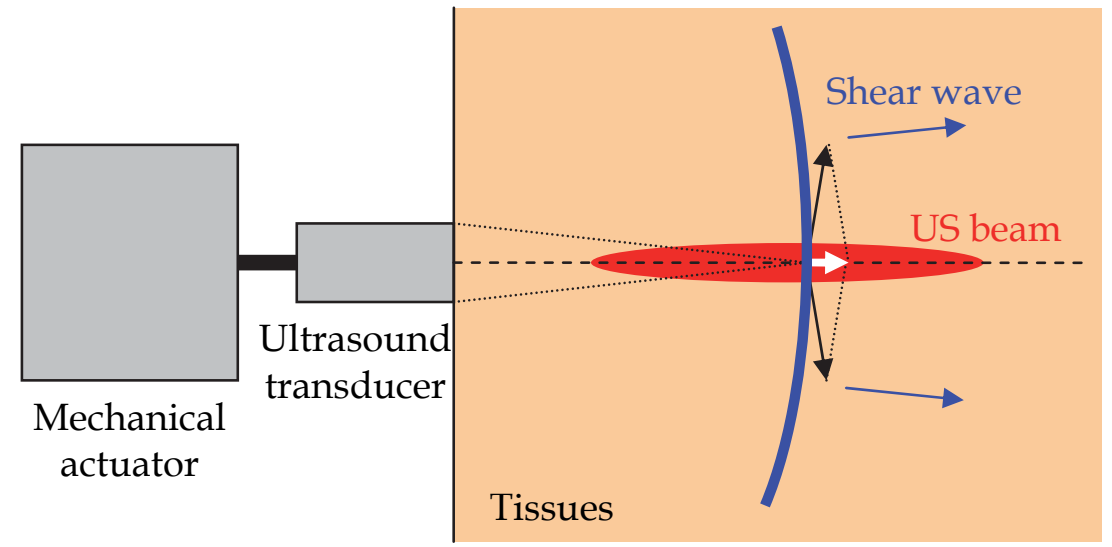

Fig. 2. The low frequency shear wave (blue) and the ultrasound beams (red) are generated by the same piston-like transducer. Under the assumption of homogeneity, the symmetry considerations impose that the displacements on the axis of the transducer be purely longitudinal (white arrow).

This technique is implemented in a standalone clinical device: Fibroscan ${ }^{\circledR}$. It is the unique device that does not require integration into a conventional imaging system. Fibroscan ${ }^{\circledR}$ device is detailed in the next section.

\subsection{The importance of the vibration control in quantitative elastography}

The proper use of shear wave velocity analysis for clinical diagnosis requires the control of various physical parameters and in particular the control of the vibration to ensure an accurate, reliable and reproducible assessment of tissue stiffness. The control must be done on the shape, frequency and amplitude of the vibration. Of course, in VCTE ${ }^{\mathrm{TM}}$, the amplitude of the vibration may be adapted to the morphology of the patients to increase the penetration depth of the shear wave.

Furthermore, as stiffness value depends on shear wave frequency, the shape of the vibration must be controlled to obtain a consistent measurement that can be used for diagnostic purposes whatever the mechanical properties of the organ under investigation or the etiology of the patient. Provided that the shape of the vibration be constant, a reference frequency is obtained and a comparison of the shear wave propagation parameters can be performed independently of the organ conditions, etiology, patient and operator.

\subsection{The difficult process of liver stiffness measurement standardization}

The development and clinical validation of non-invasive methods for assessing liver fibrosis in patients with chronic liver diseases were eased by the fact that liver biopsy is not a perfect 
gold standard. However, standardization of elastography procedures is a challenging aspect of the success of elastography in the medical field and more precisely in hepatology.

Radiation force based elastography techniques such as ARFI and SSI are attractive techniques since they are intrinsically image-guided and do not require the use of an external vibrator. Actually these attractive aspects of the technology may result in significant loss of performances.

As a matter of fact, using an image guided system in which the operator has a full freedom of choice of the region of measurement will increase the operator dependency of the technique. While VCTETM may look less sophisticated, it is based on a highly standardized procedure that can be followed not only by physicians but also by nurses. A short training is required before using Fibroscan ${ }^{\circledR}$. This standardization favors the consistency of the results obtained whatever the operator, the studied population and the etiology of the patients.

Shear waves remotely generated using radiation force are wide band with frequencies ranging from $100 \mathrm{~Hz}$ to $500 \mathrm{~Hz}$. Indeed with radiation force, the frequency of the shear waves can not be controlled precisely. Thus the frequency content of the generated shear wave will vary as a function of parameters such as the acoustic attenuation, the nature of reflecting materials, the mechanical properties of the tissues through which the ultrasound and shear waves travel, the depth of the region of measurement, etc. Some of these parameters are obviously etiology-dependent. As a consequence, measured stiffness will vary. Moreover, it is now well described that liver stiffness increases when the shear wave frequency increases (see Fig. 3). Thus, the higher the frequency is, the higher the measured stiffness will be.

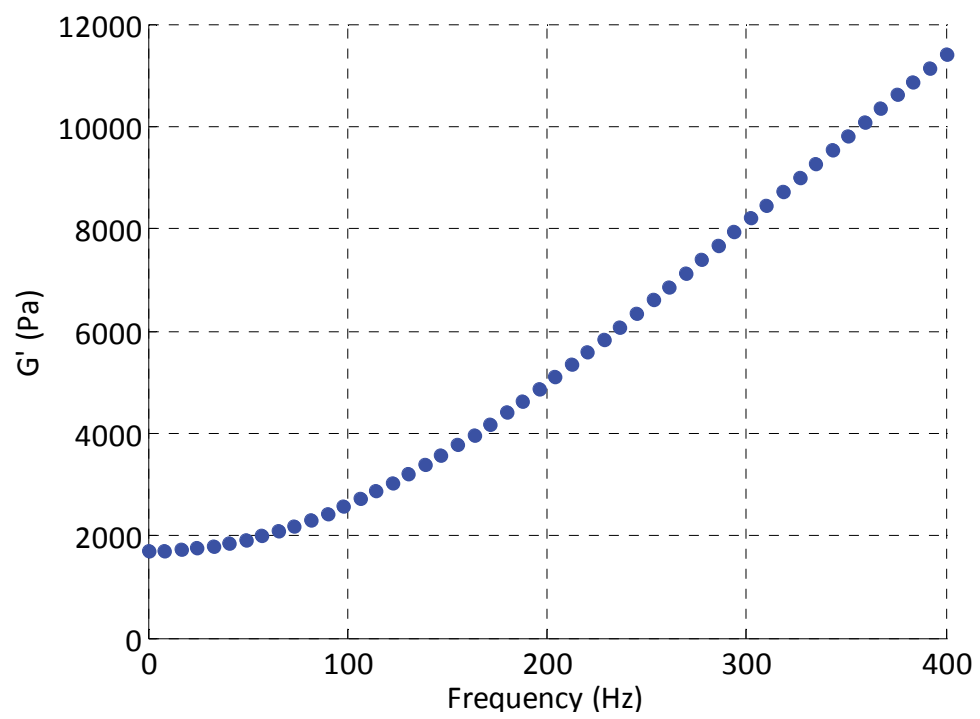

Fig. 3. Preliminary result: elastic modulus of a fresh pig liver sample as a function of frequency (courtesy of RheoLution inc).

Eventually, though a direct conversion of liver stiffness values measured with transient elastography techniques based on radiation force and mechanical vibration is tempting, this task might be a very challenging task. Indeed, theoretically Young's modulus as provided 
by VCTE ${ }^{\mathrm{TM}}$ could be deduced from the shear velocity as measured by radiation force-based technique (ARFI, SSI, etc.). However, this relationship is only valid at a given frequency:

$$
E(f)=3 \rho V_{s}(f)^{2}
$$

As a matter of fact, while shear wave frequency in VCTETM is $50 \mathrm{~Hz}$, shear wave frequency using radiation force is not controlled. Thus, as the frequencies may be significantly different with these techniques, a direct conversion of radiation-force-based shear wave velocity to VCTETM Young's modulus is not possible. The Young's modulus obtained with VCTE $^{\mathrm{TM}}$ and radiation-force based elastograhy will differ. Therefore liver stiffness thresholds used for clinical decision support will have to be reevaluated.

The success of VCTETM and the good performances reported in many studies all over the world is certainly due to its high standardization and high control of the shear wave shape.

\section{Fibroscan® device}

In this Section, the Fibroscan ${ }^{\circledR}$ device is described from a technical point of view. The operating principle is detailed with appropriate figures. Tables are included to provide parameters of the different probes available associated with measurement depths, operating ultrasound frequency, probe diameter, etc. A list of the special controls used in the Fibroscan ${ }^{\circledR}$ to ensure high performances is included. The examination procedure is described.

\subsection{The device}

Transient elastography measures shear wave velocity and thus determines tissue stiffness by using ultrasound to follow the propagation of a low frequency shear wave generated in a tissue by an external vibrator (Sandrin et al. 2002; Ziol et al. 2005). The Fibroscan ${ }^{\circledR}$ (Fig. 4) is composed of an integrated computer and dedicated electronics for ultrasound emission end reception, vibrator command and signal processing.
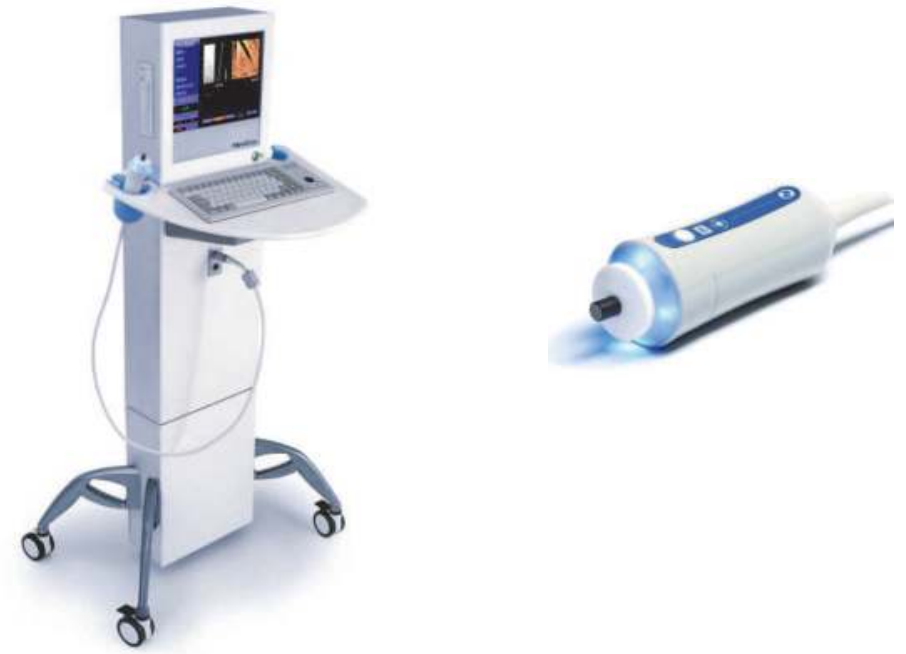

Fig. 4. The Fibroscan ${ }^{\circledR}$ and its M-probe. 
The Fibroscan ${ }^{\circledR}$ probe contains an ultrasonic transducer used both as receiver and emitter which is mounted on a mechanical vibrator to generate a low frequency $(50 \mathrm{~Hz})$ shear wave. During the propagation of the low frequency shear wave, the radiofrequency (RF) data are acquired at a repetition frequency of $6000 \mathrm{~Hz}$. The displacements induced in the medium are computed from the RF data using an autocorrelation method and derived versus depth in order to provide a strain rate image called elastogram (Fig. 5(c)). Analysis of the strain image yields the shear wave velocity and thus elasticity using the formula $\mathrm{E}=3 \rho \mathrm{Vs}^{2}$ where E, $\rho=1000 \mathrm{~kg} / \mathrm{m}^{3}$, and Vs are the Young's modulus, the mass density and the shear wave, respectively. In order to compute the shear wave velocity, a time-of-flight algorithm is used (Sandrin et al. 2003). The system enables to measure stiffness values (Young's modulus) between $1.5 \mathrm{kPa}$ and $75 \mathrm{kPa}$.

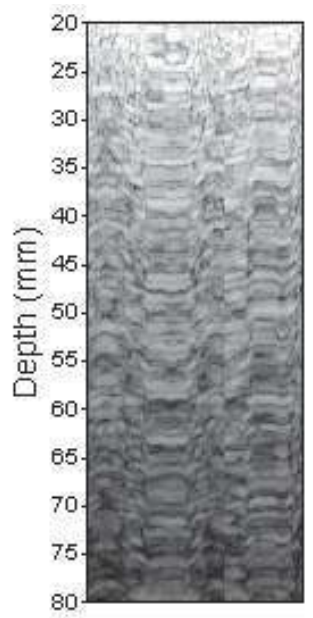

(a)

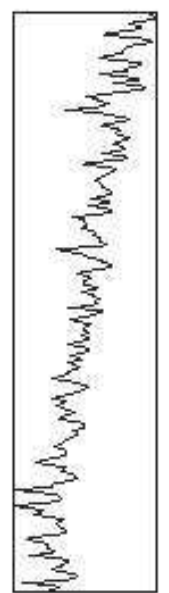

(b)

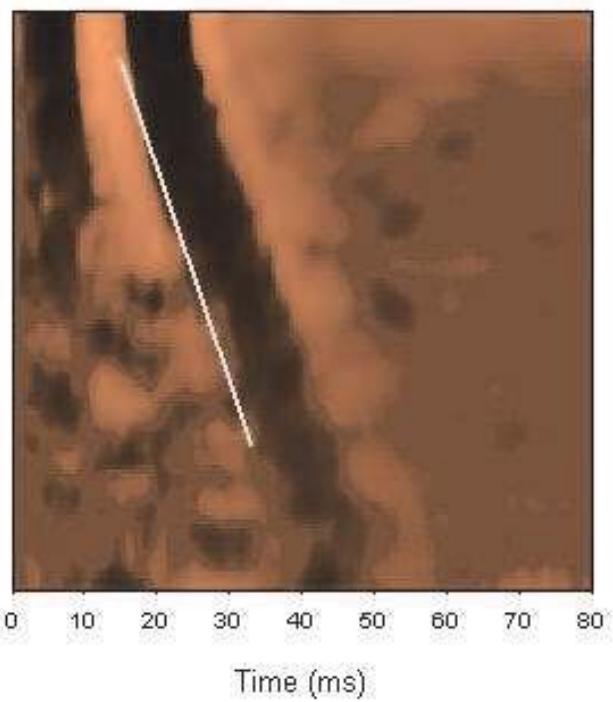

(c)

Fig. 5. (a) TM-mode, (b) A-mode and (c) elastogram images. The elastogram is a 2D graphical representation of the strain rates as a function of depth and time. The slope of the shear wave is represented by a white dotted line.

As shown in Table 3, four types of examination with specific depth and ultrasound frequency are available according to the morphology of the patient: skin-capsule distance (SCD) and thoracic perimeter (TP).

\begin{tabular}{|c|c|c|c|c|}
\hline Probe & Exam.Type & Criteria & Examination depth & Frequency \\
\hline \multirow{2}{*}{$\mathbf{S}$} & Small 1 (S1) & $\mathrm{TP} \leq 45 \mathrm{~cm}$ & From $15 \mathrm{~mm}$ to $40 \mathrm{~mm}$ & \multirow{2}{*}{$5 \mathrm{MHz}$} \\
\cline { 2 - 4 } & Small $2(\mathrm{~S} 2)$ & $45 \mathrm{~cm}<\mathrm{TP} \leq 75 \mathrm{~cm}$ & From $20 \mathrm{~mm}$ to $50 \mathrm{~mm}$ & \multirow{2}{*}{$3.5 \mathrm{MHz}$} \\
\hline \multirow{2}{*}{$\mathbf{M}$} & Medium $(\mathrm{M})$ & $\begin{array}{c}75 \mathrm{~cm}<\mathrm{TP} \leq 110 \mathrm{~cm} \\
\text { and SCD }<2.5 \mathrm{~cm}\end{array}$ & From $25 \mathrm{~mm}$ to $65 \mathrm{~mm}$ & $2.5 \mathrm{MHz}$ \\
\hline $\mathbf{X L}$ & $\mathrm{XL}$ & $2.5 \mathrm{~cm} \leq \mathrm{SCD}<3.5 \mathrm{~cm}$ & From $35 \mathrm{~mm}$ to $75 \mathrm{~mm}$ & 2 \\
\hline
\end{tabular}

Table 3. Fibroscan ${ }^{\circledR}$ examination parameters. 


\subsection{Examination procedure}

During the examination, the patient is lying in dorsal decubitus and the right arm in maximal abduction so as to enlarge the intercostals space in which the probe is placed (Fig. 6). The ribs play an important role since they prevent the application of large pressure on the liver by the probe. Indeed, biological tissues have a non linear elastic behavior when they are submitted to large strains. This nonlinearity would result in a biased measurement of the stiffness. This phenomenon also explains why elasticity measurements cannot be performed on the left lobe of the liver which is not protected by the ribs.

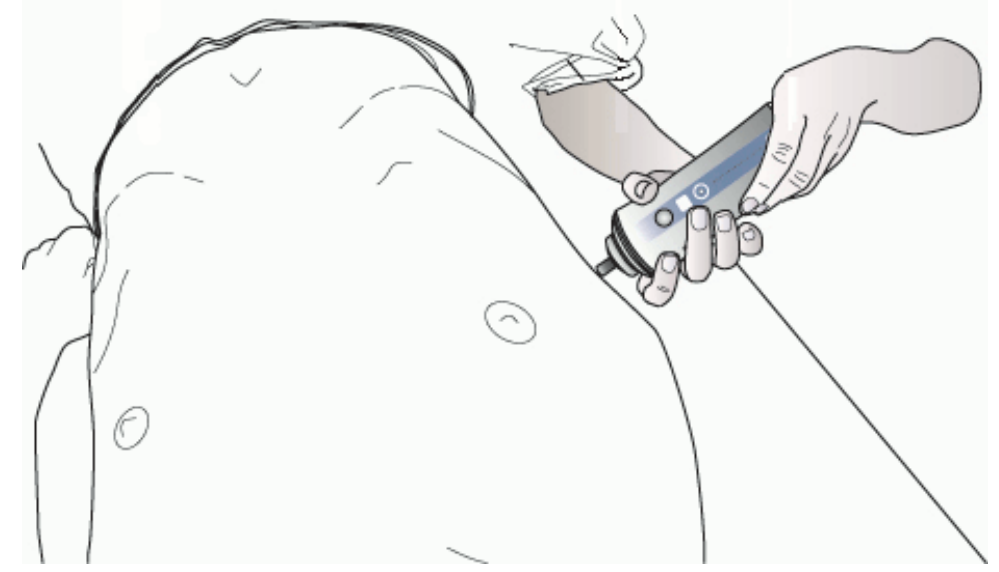

Fig. 6. During Fibroscan ${ }^{\circledR}$ examination, the patient is lying in dorsal decubitus and the right arm in maximal abduction so as to enlarge the intercostals space in which the probe is placed.

The probe should be placed between the rib bones opposite to the right lobe of the liver in the middle of the parenchyma far from the border of the liver. The measurement point should actually be similar to the location where the liver biopsy would be performed. Measurements performed too close to the borders the liver stiffness should be avoided as they will be overestimated.

The Fibroscan ${ }^{\circledR}$ device provides A-mode and M-mode images which should be used to find a liver portion suitable for the examination (Fig. 7). This liver area should be at least $60 \mathrm{~mm}$ deep and free of large vascular structures. In the case of a standard examination, the stiffness measurements are performed between $25 \mathrm{~mm}$ and $65 \mathrm{~mm}$ below the skin surface. The force applied by the probe on the skin is controlled during the whole examination and must be comprised between $4 \mathrm{~N}$ and $8 \mathrm{~N}$ in order to trigger a stiffness measurement.

During the examination, the operator should be careful about keeping the probe perpendicular to the skin surface or the liver stiffness may be overestimated (Fig. 8). The perpendicularity along both axes should be checked by looking at the probe. The operator should also check on the A-mode and TM-mode that the area is homogeneous and free of vessels structures (Fig. 9). 


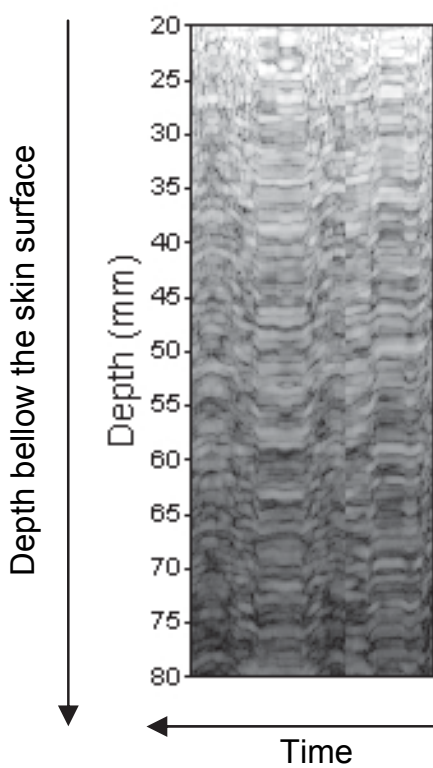

(a)

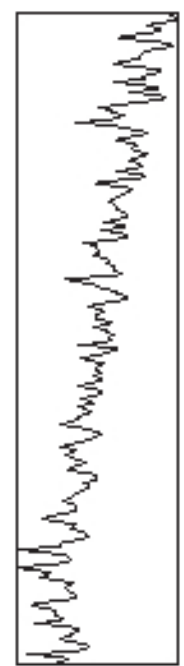

(b)

Fig. 7. The operator uses (a) TM-mode and (b) A-mode images to localize the measurement point. TM-mode represents the ultrasonic amplitude in log scale as a function of depth and time. A-mode is the real time ultrasonic line amplitude in log scale as a function of depth.
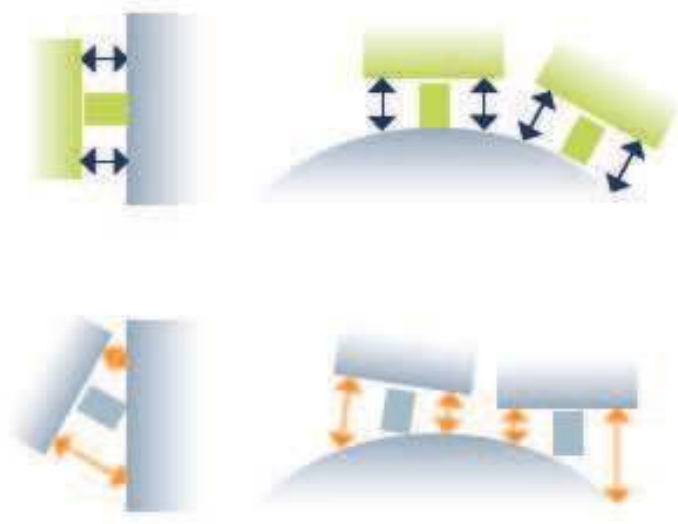

Fig. 8. During the examination, the operator should be careful about keeping the probe perpendicular to the skin surface or the liver stiffness may be overestimated. 


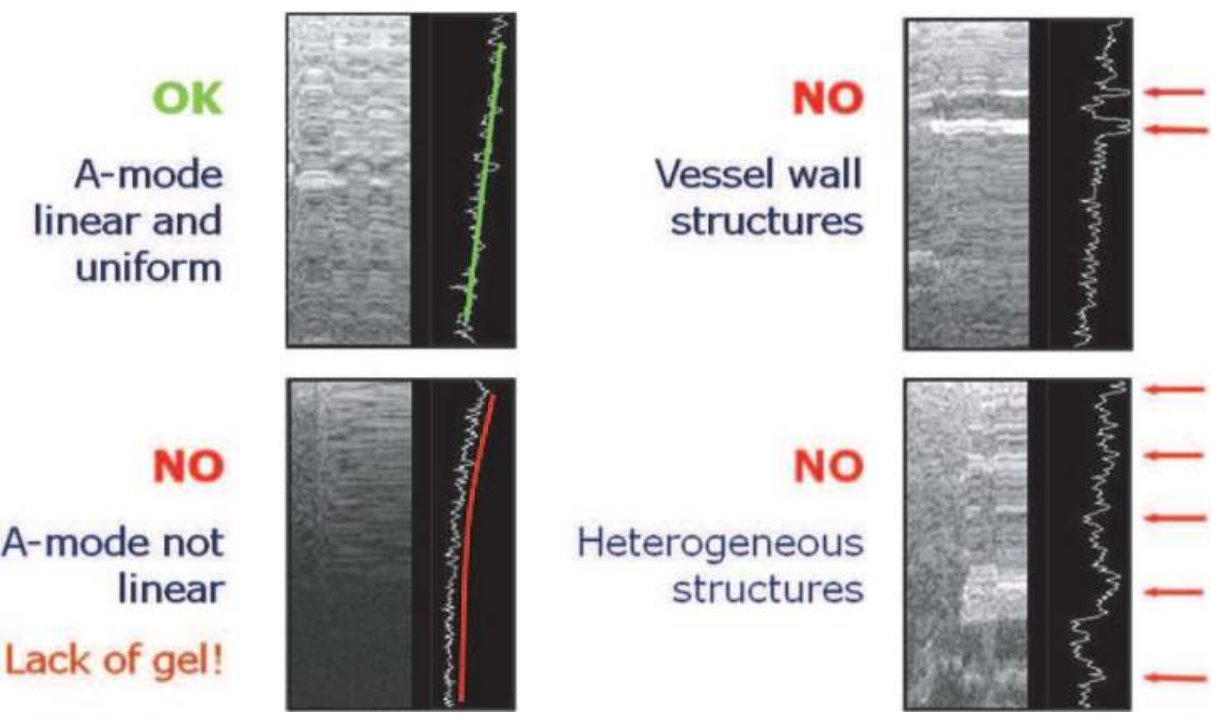

Fig. 9. The good window of acquisition is localized using A-mode and TM-mode displays.

When all the conditions mentioned above are met, the operator can trigger a measurement. An acquisition is almost instantaneous; it lasts a tenth of second. The software automatically rejects elastograms not fulfilling quality criteria and if the measurements are invalid, no result is displayed. The result of the examination is the median of all valid stiffness measurements within the current examination. The Inter Quartile Range (IQR) of all valid measurements and the success rate are also computed. Echosens recommends that a minimum of 8 valid measurements be obtained to get a consistent liver stiffness estimate.

Fibroscan ${ }^{\circledR}$ examination typically lasts between 2 and 5 minutes with recent devices. The liver explored volume by VCTE ${ }^{\mathrm{TM}}$ can be roughly approximated to be a cylinder of length $40 \mathrm{~mm}$ and diameter $10 \mathrm{~mm}$ (the actual value depends on the shear wavelength and examination type). This volume is 200 times larger than a $20 \mathrm{~mm}$ long and $1 \mathrm{~mm}$ diameter biopsy specimen.

Main limitations of Fibroscan ${ }^{\circledR}$ are the presence of ascites and obesity. Actually shear waves do not propagate through liquids. Thus Fibroscan ${ }^{\circledR}$ examination fails in some patients with ascites. However this limitation is counter balanced by the fact that ascites is already in itself an indication of liver pathological state. Thick subcutaneous tissues can result in a strong aberration of ultrasound and/or shear waves. As a result, it may be impossible to acquire enough valid measurements with Fibroscan ${ }^{\circledR}$ in some obese patients. However, a new probe, called XL probe, is now available to overcome this limitation. XL probe measures $60 \%$ of the patients not measured with M probe (de Ledinghen et al. 2010).

\section{Applications in hepatology}

A review of literature is made. In this review, the use of liver stiffness measured with Fibroscan ${ }^{\circledR}$ is studied for diagnosis, prognostic, prognosis and treatment follow-up purposes. 


\subsection{Repeatability and reproducibility}

Several groups have reported that liver stiffness measurements using Fibroscan ${ }^{\circledR}$ are repeatable and reproducible. The intra operator variability has been assessed (Boursier et al. 2008; Fraquelli et al. 2007) with intra-class correlation coefficient of 0.94 and 0.98 on 20 and 200 patients, respectively. The same publications as well as (Huwart et al. 2006) also evaluated the inter operator reproducibility with intra-class correlation coefficient ranging from 0.93 to 0.98 . It shows that liver stiffness measurement using Fibroscan ${ }^{\circledR}$ is not dependent of the operator once the latter has been properly trained.

\subsection{Diagnosis of liver fibrosis}

\subsubsection{Patients with chronic liver diseases}

As shown in Fig. 10, liver stiffness increases with the fibrosis stage obtained using liver biopsy. Liver stiffness has been shown to be closely related to fibrosis stage assessed by liver biopsy in patients suffering from chronic hepatitis C (Shaheen et al. 2007) and B (Marcellin et al. 2009), chronic cholestatic diseases (Corpechot et al. 2006), alcoholic liver disease (Melin et al. 2005; Mueller et al. 2010; Nguyen-Khac et al. 2008) and, recently, non-alcoholic fatty liver disease (Musso et al.). The most complete meta-analysis on the diagnosis accuracy of liver stiffness measured with Fibroscan ${ }^{\circledR}$ to assess liver fibrosis in patients with chronic liver disease of various etiology using liver biopsy as the gold standard (Friedrich-Rust et al. 2008) compiled up to 38 studies (publications or abstracts) (Table 4). For the diagnosis of significant fibrosis, the average AUROC was $0.84(0.82-0.86)$ (and 0.91 when adjusted for liver biopsy quality) with an optimal cut-off of $7.7 \mathrm{kPa}$. For the diagnosis of cirrhosis, the average AUROC was 0.94 (0.93-0.95) (and 0.99 when adjusted for liver biopsy quality) with an optimal cut-off of $13.0 \mathrm{kPa}$.

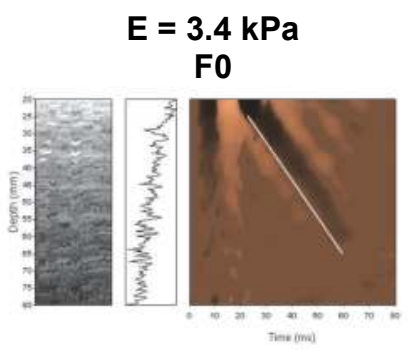

(a)
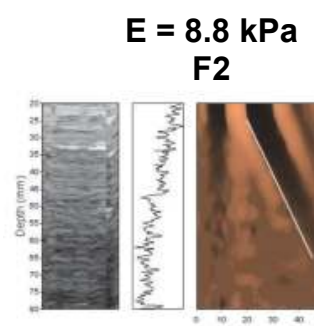

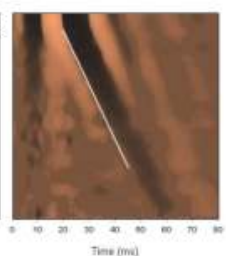

(b)

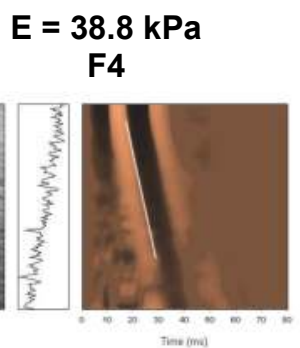

(c)

Fig. 10. The stiffer the liver the faster the shear wave (white line). From $3.4 \mathrm{kPa}$ in a healthy subject to $8.8 \mathrm{kPa}$ and $38.8 \mathrm{kPa}$ in a F2 and a F4 patients, respectively. The slope given by the shear wave front gets steeper as the stiffness increases.

\begin{tabular}{|c|c|c}
\hline Fibrosis grade & $\begin{array}{c}\text { AUROC } \\
\text { (confidence interval) }\end{array}$ & $\begin{array}{c}\text { AUROC corrected for } \\
\text { liver biopsy quality }\end{array}$ \\
\hline $\mathrm{F} \geq \mathrm{F} 2$ & $0.84(0.82-0.86)$ & 0.91 \\
\hline $\mathrm{F}=4$ & $0.94(0.93-0.95)$ & 0.99 \\
\hline
\end{tabular}

Table 4. Diagnosis accuracy of liver stiffness measured with Fibroscan ${ }^{\circledR}$ to assess liver fibrosis in patients with chronic liver disease of various etiology using liver biopsy as the gold standard. Compilation of 38 studies (publications or abstracts). 


\subsubsection{General population}

Roulot (Roulot et al. 2010; Roulot et al. 2008) performed a study which aimed at detecting fibrosis in the general population. 1368 subjects attending a free check up in a medical center were measured. Liver biopsy was proposed to subjects $(\mathrm{N}=80)$ with stiffness values above $8 \mathrm{kPa}$. 28 subjects accepted to go through liver biopsy. Interestingly, all of them had fibrosis and cirrhosis was found in all subjects with stiffness above $14.6 \mathrm{kPa}$. Among the 72 subjects between $8 \mathrm{kPa}$ and $14.6 \mathrm{kPa}: 45$ were overweight with metabolic syndrome, 18 were alcoholic, 5 had HCV and 4 had HBV.

\subsection{Prognosis value}

\subsubsection{Complication of cirrhosis}

In addition to being related to portal hypertension assessed by HVPG measurement (Bureau et al. 2008; Carrion et al. 2006; Vizzutti et al. 2008), liver stiffness was shown to be related to other complications of cirrhosis. In a study (Foucher et al. 2006) on 144 patients with biopsy proven cirrhosis or bridging fibrosis, liver stiffness measurement had an AUROC of 0.90, $0.89,0.71$ and 0.88 for the detection of Child-Pugh score A versus BC, past history of ascites, presence of hepatocellular carcinoma and past history of ascites, respectively.

\subsubsection{Liver transplantation}

Rigamonti et al (Rigamonti et al. 2008) reported that liver stiffness accurately predicts fibrosis progression in liver transplanted patients with recurrent hepatitis $C$, suggesting that protocol liver biopsy might be avoided in patients with improved or stable transient elastography values during follow-up..

\subsubsection{Survival}

Vergniol et al (Vergniol et al.) followed 1457 patients (median 47.3 months) and demonstrated that the prognostic value of liver stiffness on survival was superior to that of liver biopsy. As a good predictive factor of survival, liver stiffness may help physician to evaluate earlier the severity of chronic liver diseases, to decide with stronger arguments of a liver transplantation or a portosystemic shunt and to evaluate more precisely the surgical risk of our cirrhotic patients.

\subsection{Treatment follow-up}

Fibroscan ${ }^{\circledR}$ was successfully used to assess liver fibrosis in patients during HCV or HBV therapy (Barreiro et al. 2006; Oliveri et al. 2008; Soriano et al. 2006). Ogawa et al (Ogawa et al. 2009) demonstrated that liver stiffness values measured by Fibroscan(r) may predict a progressively better clinical outcome for patients with successful virological and biochemical responses. Vergniol et al (Vergniol et al. 2009) suggested that Fibroscan(r) should be useful for assessing treatment efficacy in clinical trials of new drugs.

Recently, Berends et al (Berends et al. 2007) reported that Fibroscan(r) accurately predicted the absence of significant liver fibrosis in methotrexate users.

\section{The pressure-stiffness-fibrosis sequence hypothesis}

\subsection{Factors influencing liver stiffness}

As reported in the literature, liver stiffness is very well correlated with liver fibrosis. However studies showed that other factors influence liver stiffness. Several groups reported 
that liver stiffness significantly increases during inflammatory episodes (Arena et al. 2008; Oliveri et al. 2008; Sagir et al. 2008). They showed that during several months monitoring, liver stiffness values paralleled those of ALT in patients with hepatitis exacerbation and observed a progressive decrease during antiviral therapy. Millonig (Millonig et al. 2009; Millonig et al. 2008) reported that mechanical cholestasis drastically and reversibly increases liver stiffness and that liver stiffness is influenced by central venous pressure and thus liver congestion, for example due to cardiac insufficiency.

\subsection{Physical point of view}

From a physical point of view, liver stiffness is obviously mainly driven by the liver extracellular matrix which provides structural support to the liver. However, since the liver is self-contained in a non extensible Glisson's capsule, stiffness is definitively influenced by pressure that can be either hydrostatic or osmotic. The amount of collagen contained in the matrix yields a static stiffness. As shown in Fig. 11, on top of this static stiffness, hydrostatic and osmotic pressure effects will add a pressure-related stiffness term which results from body flood dynamics: blood flow, interstitial liquids, etc. On one hand, central venous pressure is directly related to hydrostatic pressure resulting from heart beating. On the other hand, flow of fluid from plasma to interstitial fluid is driven by osmotic pressure. During inflammatory episodes, accumulation of interstitial liquid and inflammatory infiltrate increases osmotic pressure.

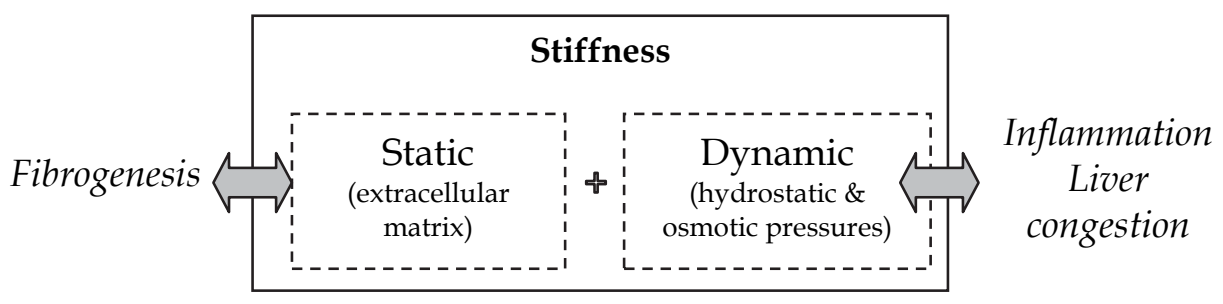

Fig. 11. Liver stiffness is composed of two components: static stiffness due to the extracellular matrix and dynamic stiffness linked to hydrostatic pressure and osmotic pressure.

\subsection{Molecular mechanism}

A study from Sakata (Sakata et al. 2004) supports the pressure-matrix-stiffness sequence hypothesis (Mueller \& Sandrin 2010). Under this hypothesis, pressure results in increased mechanical stretching which induces transforming growth factor (TGF)- $\beta$ synthesis in hepatic stellate cells, which is known to be highly expressed under profibrogenic conditions. Therefore, increased dynamic stiffness due to pressure induces mechanical stretches which stimulate the production of collagen (fibrotic tissue) which results in a static stiffness increase as if the liver was adapting its structure to inner body mechanical conditions.

Among the numerous questions that still need to be answered on this very exciting subject, one of the more interesting may be the understanding of the respective roles of portal fibrosis and perisinusoidal fibrosis in liver stiffness. 


\section{Discussion}

Liver stiffness measurement using Fibroscan ${ }^{\circledR}$ has been studied in all major causes of chronic liver diseases: chronic hepatitis C, chronic hepatitis B, HIV - HCV co-infection, alcoholic liver disease (ALD), non alcoholic fatty liver disease (NAFLD), biliary disease, etc.

\subsection{The keys of Fibroscan $®$ success and its limitations}

The success of liver stiffness measurement using Fibroscan ${ }^{\circledR}$ may be explained by several factors. First of al, it is a bedside procedure which lasts between 2 and 5 minutes and gives an immediate result. Second, the procedure is highly standardized with dedicated training which provides low operator dependence compared to ultrasound guided procedures, as an example. Third it offers new perspectives as liver stiffness is providing more information to physicians than fibrosis. Furthermore, it can be used for diagnosis, prognostic and follow-up. As any other procedure, liver stiffness measurement using Fibroscan ${ }^{\circledR}$ is having limitations. Main physical limitation is linked to the presence of ascites as liquids prevent the propagation of shear waves. As a consequence, shear waves are stopped before they can enter liver. Another limitation is related to obesity and more specifically to a large skin to liver capsula distance. In this case, ultrasound and shear wave aberration may occur and significantly reduce the success rate of liver stiffness measurements. A new probe, XL probe, was released to overcome this issue and demonstrated a significant improvement of the measurement success in obese patients.

\subsection{Liver stiffness is a clinically relevant parameter by itself}

In 2003, liver stiffness measured using Fibroscan ${ }^{\circledR}$ was introduced as an alternative to liver biopsy in order to assess liver fibrosis non-invasively. Nowadays liver stiffness is considered as a novel objective physical parameter that will eventually be used like arterial pressure or temperature. Primarily related by liver fibrosis, liver stiffness is influenced by venous pressure, inflammation and mechanical cholestatis. It is now part of the tools a physician may use to diagnose liver diseases. For this purpose, it should obviously be interpreted in the full context of clinical, imaging and laboratory findings (Fig. 12).

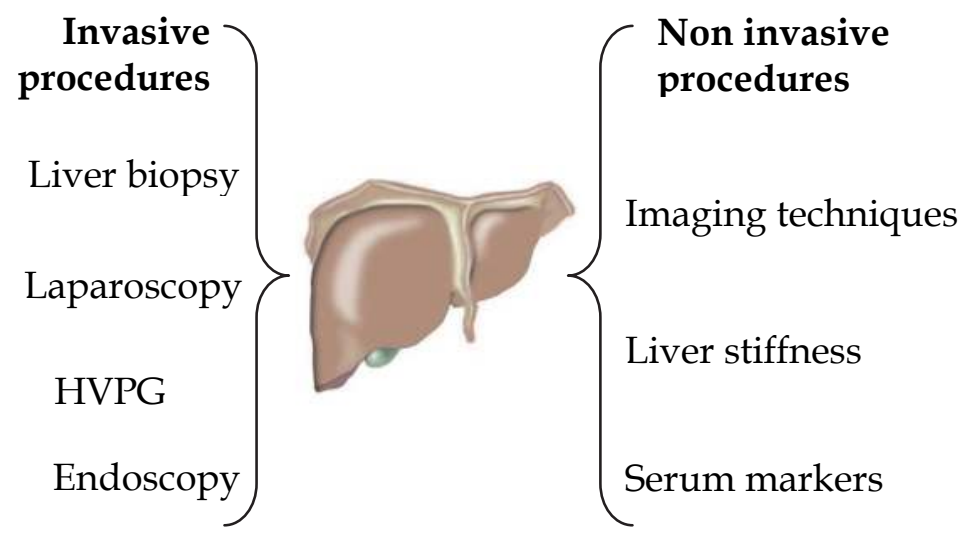

Fig. 12. Liver stiffness should always be interpreted in the context of clinical, imaging and laboratory findings. 
As explained earlier in this chapter, liver stiffness is not only affected by the liver matrix but also by pressure increase which may be attributed to several factors from congestion to inflammation. Furthermore, there are very disruptive elements that suggest that liver stiffness may not only be the consequence fibrosis deposits within the liver but also one of the causes of fibrogenesis as it has been demonstrated that hepatic stellate cells tend to generate fibrosis when they are under mechanical stress. For these reasons liver stiffness shall not be considered as a secondary endpoint; liver stiffness is a clinically relevant parameter by itself.

\subsection{Recent developments}

Even though liver stiffness provides an alternative to liver biopsy for fibrosis staging, it can not yield very important histologic features such as macrovesicular steatosis, ballooned hepatocytes, inflammation, etc. Recently, a new parameter, Controlled Attenuation Parameter (CAP), was designed to quantify liver steatosis using Fibroscan ${ }^{\circledR}$. This measurement is performed at the exact same location where liver stiffness is measured and showed good performances for steatosis quantification (Sasso et al. 2010).

The need for small animal non-invasive preclinical tools is growing. Obviously a Fibroscan ${ }^{\circledR}$ based instrumentation device adapted to small animal would have very interesting applications for the development of new drugs and for the study of drug-induced liver injury. Recently, Bastard (Bastard et al. 2011) demonstrated that VCTETM can be adapted for small animal liver stiffness measurements.

\section{Conclusion}

Initially studied for its potential benefit for breast and prostate cancer, quantitative elastography eventually led to a promising diagnostic device in hepatology. The name Fibroscan ${ }^{\circledR}$ was invented at the time when liver stiffness measurement was intended to serve as an alternative to fibrosis staging using liver biopsy. Obviously, today the name Fibroscan ${ }^{\circledR}$ is misleading as liver stiffness has become a clinically relevant parameter by itself. Liver stiffness opened new possibilities in the field of hepatology: in routine and in research. These possibilities were made possible because of key advantages of non-invasive liver stiffness measurement with Fibroscan ${ }^{\circledR}$. Among the important outcomes, the possible differentiation between early and advanced cirrhosis, the good prognostic value of liver stiffness on patient survival and the follow-up of patients undergoing treatments can be pointed out. Liver stiffness shall continue to be studied in many ways and will help physicians to better understand the natural history of liver diseases. With significant developments in the field of hepatology, for example the steatosis quantification, Fibroscan ${ }^{\circledR}$ may become the companion of hepatologists in their day to day clinical practice and research projects.

\section{Acknowledgments}

The authors are grateful to Anis Hadj Henni (RheoLution Inc) for providing useful data.

\section{References}

Abdi, W., Millan, J. C. \& Mezey, E. (1979). Sampling variability on percutaneous liver biopsy, Arch Intern Med, Vol.139, No.6, (Jun), pp. 667-9 
Arena, U., Vizzutti, F., Corti, G., Ambu, S., Stasi, C., Bresci, S., Moscarella, S., Boddi, V., Petrarca, A., Laffi, G., Marra, F. \& Pinzani, M. (2008). Acute viral hepatitis increases liver stiffness values measured by transient elastography, Hepatology, Vol.47, No.2, (Feb), pp. 380-4

Barreiro, P., Labarga, P., Martin-Carbonero, L., Amor, A., Ruiz-Sancho, A., Castellares, C., Gonzalez-Lahoz, J. \& Soriano, V. (2006). Sustained virological response following $\mathrm{HCV}$ therapy is associated with non-progression of liver fibrosis in HCV/HIVcoinfected patients, Antivir Ther, Vol.11, No.7, pp. 869-77

Bastard, C., Bosisio, M. R., Chabert, M., Kalopissis, A., Mahrouf-Yorgov, M., Gilgenkrantz, H., Mueller, S. \& Sandrin, L. (2011). Transient micro-elastography: A novel approach to measure liver stiffness in mice, World Journal of Gastroenterology, Vol.17, No.8, pp. 968-975

Bedossa, P., Dargere, D. \& Paradis, V. (2003). Sampling variability of liver fibrosis in chronic hepatitis C, Hepatology, Vol.38, No.6, (Dec), pp. 1449-57

Bercoff, J., Tanter, M. \& Fink, M. (2004). Supersonic shear imaging: a new technique for soft tissues elasticity mapping, IEEE Transactions on Utrasonics, Ferroelectrics, and Frequency Control, Vol.51, No.4, pp. 374-409

Berends, M. A., Snoek, J., de Jong, E. M., Van Krieken, J. H., de Knegt, R. J., van Oijen, M. G., van de Kerkhof, P. C. \& Drenth, J. P. (2007). Biochemical and biophysical assessment of MTX-induced liver fibrosis in psoriasis patients: Fibrotest predicts the presence and Fibroscan predicts the absence of significant liver fibrosis, Liver Int, Vol.27, No.5, (Jun), pp. 639-45

Boursier, J., Konate, A., Gorea, G., Reaud, S., Quemener, E., Oberti, F., Hubert-Fouchard, I., Dib, N. \& Cales, P. (2008). Reproducibility of liver stiffness measurement by ultrasonographic elastometry, Clin Gastroenterol Hepatol, Vol.6, No.11, (Nov), pp. 1263-9

Bravo, A. A., Sheth, S. \& Chpra, S. (2001). Liver biopsy, The New England Journal of Medicine, Vol.344, No.7, pp. 495-500

Bureau, C., Metivier, S., Peron, J. M., Selves, J., Robic, M. A., Gourraud, P. A., Rouquet, O., Dupuis, E., Alric, L. \& Vinel, J. P. (2008). Transient elastography accurately predicts presence of significant portal hypertension in patients with chronic liver disease, Aliment Pharmacol Ther, Vol.27, No.12, (Jun), pp. 1261-8

Cadranel, J. F., Rufat, P. \& Degos, F. (2001). Pratiques de la ponction-biopsie hépatique transpariétale en France, Gastroenterologie Clinique et Biologique, Vol.25, pp. 77-80

Carrion, J. A., Navasa, M., Bosch, J., Bruguera, M., Gilabert, R. \& Forns, X. (2006). Transient elastography for diagnosis of advanced fibrosis and portal hypertension in patients with hepatitis C recurrence after liver transplantation, Liver Transpl, Vol.12, No.12, (Dec), pp. 1791-8

Castera, L., Vergniol, J., Foucher, J., Le Bail, B., Chanteloup, E., Haaser, M., Darriet, M., Couzigou, P. \& de Ledinghen, V. (2005). Prospective comparison of transient elastography, Fibrotest, APRI and liver biopsy for the assessement of fibrosis in chronic hepatitis C, Gastroenterology, Vol.128, pp. 343-350

Corpechot, C., El Naggar, A., Poujol-Robert, A., Ziol, M., Wendum, D., Chazouilleres, O., de Ledinghen, V., Dhumeaux, D., Marcellin, P., Beaugrand, M. \& Poupon, R. (2006). Assessment of biliary fibrosis by transient elastography in patients with $\mathrm{PBC}$ and PSC, Hepatology, Vol.43, No.5, (May), pp. 1118-24 
de Ledinghen, V., Vergniol, J., Foucher, J., El-Hajbi, F., Merrouche, W. \& Rigalleau, V. (2010). Feasibility of liver transient elastography with FibroScan using a new probe for obese patients, Liver Int, Vol.30, No.7, (Aug), pp. 1043-8

Fahey, B. J., Palmeri, M. L. \& Trahey, G. E. (2006). Frame rate considerations for real-time abdominal acoustic radiation force impulse imaging, Ultrason Imaging, Vol.28, No.4, (Oct), pp. 193-210

Foucher, J., Castera, L., Bernard, P. H., Adhoute, X., Laharie, D., Bertet, J., Couzigou, P. \& de Ledinghen, V. (2006). Prevalence and factors associated with failure of liver stiffness measurement using FibroScan in a prospective study of 2114 examinations, European Journal of Gastroenterology \& Hepatology, Vol.18, No.4, (Apr), pp. 411-412

Fraquelli, M., Rigamonti, C., Casazza, G., Conte, D., Donato, M. F., Ronchi, G. \& Colombo, M. (2007). Reproducibility of transient elastography in the evaluation of liver fibrosis in patients with chronic liver disease, Gut, Vol.56, No.7, (Jul), pp. 968-73

Friedrich-Rust, M., Ong, M. F., Martens, S., Sarrazin, C., Bojunga, J., Zeuzem, S. \& Herrmann, E. (2008). Performance of transient elastography for the staging of liver fibrosis: a meta-analysis, Gastroenterology, Vol.134, No.4, (Apr), pp. 960-74

Huwart, L., Peeters, F., Sinkus, R., Annet, L., Salameh, N., ter Beek, L. C., Horsmans, Y. \& Van Beers, B. E. (2006). Liver fibrosis: non-invasive assessment with MR elastography, Nmr in Biomedicine, Vol.19, No.2, (Apr), pp. 173-179

Klatt, D., Asbach, P., Rump, J., Papazoglou, S., Somasundaram, R., Modrow, J., Braun, J. \& Sack, I. (2006). In vivo determination of hepatic stiffness using steady-state free precession magnetic resonance elastography, Invest Radiol, Vol.41, No.12, (Dec), pp. $841-8$

Marcellin, P., Ziol, M., Bedossa, P., Douvin, C., Poupon, R., de Ledinghen, V. \& Beaugrand, M. (2009). Non-invasive assessment of liver fibrosis by stiffness measurement in patients with chronic hepatitis B, Liver Int, Vol.29, No.2, (Feb), pp. 242-7

Melin, P., Dacon, A., Gauchet, A., Schoeny, M. \& Diebold, M.-D. (2005). Dépistage non invasif de la fibrose : Intérêt du FibroScan en consultation d'alcoologie [Noninvasive detection of liver fibrosis: Value of FibroScan in alcohol consulting outpatients], Alcoologie et Addictologie, Vol.27, No.3, pp. 191-196

Millonig, G., Friedrich, S., Adolf, S., Fonouni, H., Golriz, M., Mehrabi, A., Stiefel, P., Poschl, G., Buchler, M. W., Seitz, H. K. \& Mueller, S. (2009). Liver stiffness is directly influenced by central venous pressure, J Hepatol, Vol.52, No.2, (Feb), pp. 206-10

Millonig, G., Reimann, F. M., Friedrich, S., Fonouni, H., Mehrabi, A., Buchler, M. W., Seitz, H. K. \& Mueller, S. (2008). Extrahepatic cholestasis increases liver stiffness (FibroScan) irrespective of fibrosis, Hepatology, Vol.48, No.5, (Nov), pp. 1718-23

Mueller, S., Millonig, G., Sarovska, L., Friedrich, S., Reimann, F. M., Pritsch, M., Eisele, S., Stickel, F., Longerich, T., Schirmacher, P. \& Seitz, H. K. (2010). Increased liver stiffness in alcoholic liver disease: differentiating fibrosis from steatohepatitis, World J Gastroenterol, Vol.16, No.8, (Feb 28), pp. 966-72

Mueller, S. \& Sandrin, L. (2010). Liver stiffness: a novel parameter for the diagnosis of liver disease, Hepatic Medicine: Evidence and Research, Vol.2, (May), pp. 49-67

Muller, M., Gennisson, J. L., Deffieux, T., Tanter, M. \& Fink, M. (2009). Quantitative viscoelasticity mapping of human liver using supersonic shear imaging: 
preliminary in vivo feasibility study, Ultrasound Med Biol, Vol.35, No.2, (Feb), pp. 219-29

Musso, G., Gambino, R., Cassader, M. \& Pagano, G. Meta-analysis: Natural history of nonalcoholic fatty liver disease (NAFLD) and diagnostic accuracy of non-invasive tests for liver disease severity, Ann Med, (Nov 2), pp.

Muthupillai, R., Lomas, D. J., Rossman, P. J., Greenleaf, J. F., Manduca, A. \& Ehman, R. L. (1995). Magnetic resonance elastography by direct visualization of propagating acoustic strain waves, Science, Vol.269, No.5232, (Sep 29), pp. 1854-7

Nguyen-Khac, E., Chatelain, D., Tramier, B., Decrombecque, C., Robert, B., Joly, J. P., Brevet, M., Grignon, P., Lion, S., Le Page, L. \& Dupas, J. L. (2008). Assessment of asymptomatic liver fibrosis in alcoholic patients using fibroscan: prospective comparison with seven non-invasive laboratory tests, Aliment Pharmacol Ther, Vol.28, No.10, (Nov 15), pp. 1188-98

Nightingale, K., McAleavey, S. \& Trahey, G. (2003). Shear-wave generation using acoustic radiation force: in vivo and ex vivo results, Ultrasound Med Biol, Vol.29, No.12, (Dec), pp. 1715-23

Ogawa, E., Furusyo, N., Toyoda, K., Takeoka, H., Maeda, S. \& Hayashi, J. (2009). The longitudinal quantitative assessment by transient elastography of chronic hepatitis $\mathrm{C}$ patients treated with pegylated interferon alpha- $2 \mathrm{~b}$ and ribavirin, Antiviral Res, Vol.83, No.2, (Aug), pp. 127-34

Oliveri, F., Coco, B., Ciccorossi, P., Colombatto, P., Romagnoli, V., Cherubini, B., Bonino, F. \& Brunetto, M. R. (2008). Liver stiffness in the hepatitis B virus carrier: a noninvasive marker of liver disease influenced by the pattern of transaminases, World J Gastroenterol, Vol.14, No.40, (Oct 28), pp. 6154-62

Palmeri, M. L. \& Nightingale, K. R. (2004). On the thermal effects associated with radiation force imaging of soft tissue, IEEE Trans Ultrason Ferroelectr Freq Control, Vol.51, No.5, (May), pp. 551-65

Palmeri, M. L., Wang, M. H., Dahl, J. J., Frinkley, K. D. \& Nightingale, K. R. (2008). Quantifying hepatic shear modulus in vivo using acoustic radiation force, Ultrasound Med Biol, Vol.34, No.4, (Apr), pp. 546-58

Poynard, T., Imbert-Bismut, F., Munteanu, M., Messous, D., Myers, R. P., Thabut, D., Ratziu, V., Mercadier, A., Benhamou, Y. \& Hainque, B. (2004). Overview of the diagnostic value of biochemical markers of liver fibrosis (FibroTest, HCV FibroSure) and necrosis (ActiTest) in patients with chronic hepatitis C, Comparative Hepatology, Vol.3, No.1, (Sep 23), pp. 8

Rigamonti, C., Donato, M. F., Fraquelli, M., Agnelli, F., Ronchi, G., Casazza, G., Rossi, G. \& Colombo, M. (2008). Transient elastography predicts fibrosis progression in patients with recurrent hepatitis C after liver transplantation, Gut, Vol.57, No.6, (Jun), pp. 821-7

Roulot, D., Costes, J. L., Buyck, J. F., Warzocha, U., Gambier, N., Czernichow, S., Le Clesiau, H. \& Beaugrand, M. (2010). Transient elastography as a screening tool for liver fibrosis and cirrhosis in a community-based population aged over 45 years, Gut, (Nov 10), pp.

Roulot, D., Czernichow, S., Le Clesiau, H., Costes, J. L., Vergnaud, A. C. \& Beaugrand, M. (2008). Liver stiffness values in apparently healthy subjects: influence of gender and metabolic syndrome, J Hepatol, Vol.48, No.4, (Apr), pp. 606-13 
Rouviere, O., Yin, M., Dresner, M. A., Rossman, P. J., Burgart, L. J., Fidler, J. L. \& Ehman, R. L. (2006). MR elastography of the liver: preliminary results, Radiology, Vol.240, No.2, (Aug), pp. 440-8

Sagir, A., Erhardt, A., Schmitt, M. \& Haussinger, D. (2008). Transient elastography is unreliable for detection of cirrhosis in patients with acute liver damage, Hepatology, Vol.47, No.2, (Feb), pp. 592-5

Sakata, R., Ueno, T., Nakamura, T., Ueno, H. \& Sata, M. (2004). Mechanical stretch induces TGF-beta synthesis in hepatic stellate cells, Eur J Clin Invest, Vol.34, No.2, (Feb), pp. 129-36

Sandrin, L., Cassereau, D. \& Fink, M. (2004). The role of the coupling term in transient elastography., Journal of the Acoustical Society of America, Vol.115, pp. 73-83

Sandrin, L., Fourquet, B., Hasquenoph, J. M., Yon, S., Fournier, C., Mal, F., Christidis, C., Ziol, M., Poulet, B., Kazemi, F., Beaugrand, M. \& Palau, R. (2003). Transient elastography: a new noninvasive method for assessment of hepatic fibrosis, Ultrasound Med Biol, Vol.29, No.12, (Dec), pp. 1705-13

Sandrin, L., Tanter, M., Catheline, S. \& Fink, M. (2002). Shear modulus imaging with 2D transient elastography, IEEE Transactions on Utrasonics, Ferroelectrics, and Frequency Control, Vol.49, pp. 426-435

Sandrin, L., Tanter, M., Gennisson, J. L., Catheline, S. \& Fink, M. (2002). Shear elasticity probe for soft tissues with 1-D transient elastography, IEEE Trans Ultrason Ferroelectr Freq Control, Vol.49, No.4, (Apr), pp. 436-46

Sarvazyan, A. P., Skovoroda, A. R., Emelianov, S. Y., Fowlkes, J. B., Pipe, J. G., Adler, R. S., Buxton, R. B. \& Carson, P. L. (1995). Biophysical bases of elasticity imaging, Acoustical Imaging, Vol.21, pp. 223-240

Sasso, M., Beaugrand, M., de Ledinghen, V., Douvin, C., Marcellin, P., Poupon, R., Sandrin, L. \& Miette, V. (2010). Controlled attenuation parameter (CAP): a novel VCTE guided ultrasonic attenuation measurement for the evaluation of hepatic steatosis: preliminary study and validation in a cohort of patients with chronic liver disease from various causes, Ultrasound Med Biol, Vol.36, No.11, (Nov), pp. 1825-35

Shaheen, A. A., Wan, A. F. \& Myers, R. P. (2007). FibroTest and FibroScan for the prediction of hepatitis C-related fibrosis: a systematic review of diagnostic test accuracy, Am J Gastroenterol, Vol.102, No.11, (Nov), pp. 2589-600

Soriano, V., Nunez, M., Garcia-Samaniego, J., Labarga, P., Simarro, N., Martin-Carbonero, L., Romero, M., Ramos, B. \& Barreiro, P. (2006). Chronic hepatitis C in HIV-infected patients: those who more need therapy are those who respond less, Infect Disord Drug Targets, Vol.6, No.1, (Mar), pp. 57-88

Vergniol, J., Foucher, J., Castera, L., Bernard, P. H., Tournan, R., Terrebonne, E., Chanteloup, E., Merrouche, W., Couzigou, P. \& de Ledinghen, V. (2009). Changes of noninvasive markers and FibroScan values during HCV treatment, J Viral Hepat, Vol.16, No.2, (Feb), pp. 132-40

Vergniol, J., Foucher, J., Terrebonne, E., Bernard, P. H., Le Bail, B., Merrouche, W., Couzigou, P. \& de Ledinghen, V. (2011). Non-Invasive Tests for Fibrosis and Liver Stiffness Predict 5-Year Outcomes of Patients with Chronic Hepatitis C, Gastroenterology, (Mar 1), pp. 
Vizzutti, F., Arena, U., Rega, L. \& Pinzani, M. (2008). Non invasive diagnosis of portal hypertension in cirrhotic patients, Gastroenterol Clin Biol, Vol.32, No.6 Suppl 1, (Sep), pp. 80-7

Ziol, M., Handra-Luca, A., Kettaneh, A., Christidis, C., Mal, F., Kazemi, F., de Ledinghen, V., Marcellin, P., Dhumeaux, D., Trinchet, J.-C. \& Beaugrand, M. (2005). Non-invasive assessment of liver fibrosis by stiffness measurements: a prospective multicenter study in patients with chronic hepatitis C, Hepatology, Vol.41, No.1, pp. 48-54 


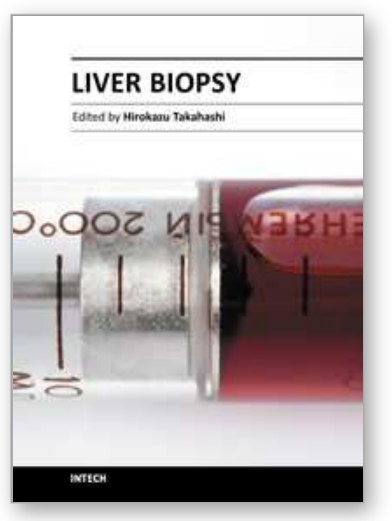

\author{
Liver Biopsy \\ Edited by Dr Hirokazu Takahashi
}

ISBN 978-953-307-644-7

Hard cover, 404 pages

Publisher InTech

Published online 06, September, 2011

Published in print edition September, 2011

Liver biopsy is recommended as the gold standard method to determine diagnosis, fibrosis staging, prognosis and therapeutic indications in patients with chronic liver disease. However, liver biopsy is an invasive procedure with a risk of complications which can be serious. This book provides the management of the complications in liver biopsy. Additionally, this book provides also the references for the new technology of liver biopsy including the non-invasive elastography, imaging methods and blood panels which could be the alternatives to liver biopsy. The non-invasive methods, especially the elastography, which is the new procedure in hot topics, which were frequently reported in these years. In this book, the professionals of elastography show the mechanism, availability and how to use this technology in a clinical field of elastography. The comprehension of elastography could be a great help for better dealing and for understanding of liver biopsy.

\title{
How to reference
}

In order to correctly reference this scholarly work, feel free to copy and paste the following:

Sandrin Laurent, Oudry Jennifer, Bastard Cécile, Fournier Céline, Miette Véronique and Mueller Sebastian (2011). Non-Invasive Assessment of Liver Fibrosis by Vibration-Controlled Transient Elastography (Fibroscan®), Liver Biopsy, Dr Hirokazu Takahashi (Ed.), ISBN: 978-953-307-644-7, InTech, Available from: http://www.intechopen.com/books/liver-biopsy/non-invasive-assessment-of-liver-fibrosis-by-vibrationcontrolled-transient-elastography-fibroscan-

\section{INTECH}

open science | open minds

\section{InTech Europe}

University Campus STeP Ri

Slavka Krautzeka 83/A

51000 Rijeka, Croatia

Phone: +385 (51) 770447

Fax: +385 (51) 686166

www.intechopen.com

\section{InTech China}

Unit 405, Office Block, Hotel Equatorial Shanghai

No.65, Yan An Road (West), Shanghai, 200040, China

中国上海市延安西路 65 号上海国际贵都大饭店办公楼 405 单元

Phone: +86-21-62489820

Fax: $+86-21-62489821$ 
(C) 2011 The Author(s). Licensee IntechOpen. This chapter is distributed under the terms of the Creative Commons Attribution-NonCommercialShareAlike-3.0 License, which permits use, distribution and reproduction for non-commercial purposes, provided the original is properly cited and derivative works building on this content are distributed under the same license. 